\title{
PRONUNCIAMIENTOS DE LA CORTE CONSTITUCIONAL SOBRE EL SERVICIO DOMÉSTICO EN COLOMBIA ${ }^{1}$ \\ Pronouncements of the Constitutional Court on Domestic Service in Colombia
}

\author{
Josefina del Carmen Quintero Lyons ${ }^{2}$ \\ Erika Patricia Bravo Blanco ${ }^{3}$ \\ Mayulis de los Ángeles Rivera Orozco ${ }^{4}$
}

Fecha de recepción: 18 de marzo de 2015

Fecha de aceptación: 12 de mayo de 2015

SUMARIO: 1. Introducción; 2. Legislación laboral colombiana sobre trabajadores del servicio doméstico; 3. Derechos laborales adquiridos por el grupo de trabajadores domésticos, a través de la jurisprudencia; 4. Conclusiones; 5. Referencias bibliográficas.

\footnotetext{
${ }^{1}$ Articulo derivado de los resultados preliminares de las investigaciones realizadas en la línea de Derecho Laboral sobre la sentencia C-871 de 2014, financiado desde el plan de fortalecimiento del grupo de investigación de Derecho del Trabajo y Seguridad Social liderado por Josefina Quintero Lyons. Grupo reconocido por Colciencias, y adscrito a la facultad de Derecho y Ciencias Políticas de la Universidad de Cartagena.

${ }^{2}$ Vicerrectora de Relaciones y Cooperación Internacional de la Universidad de Cartagena. Abogada y Docente Investigadora de la Universidad de Cartagena. Especialista en Instituciones Jurídico- Laborales por la Universidad Nacional de Colombia. Magister en Teorías Críticas del Derecho y la Democracia en Iberoamérica, Democracia e Integración Regional por Universidad Internacional de Andalucía y Doctora por la Universidad De Castilla - La Mancha, en Empleo, Relaciones Laborales y Dialogo Social en Europa. jquinterl@yahoo.com

${ }^{3}$ Egresada del Programa de Derecho y Ciencias Políticas de la Universidad de Cartagena, miembro activo del Grupo de Investigación de Derecho del Trabajo y Seguridad Social. erik.abb.16@hotmail.com

${ }^{4}$ Abogada y especialista en Ciencias Penales y Criminológicas de la Universidad de Cartagena. Miembro activo del Grupo de Investigación de Derecho del Trabajo y Seguridad Social. mayuliz.rivera@hotmail.com
} 


\section{COMO SE CITA ESTE ARTÍCULO (APA 6)}

Quintero Lyons, Josefina del Carmen; Bravo Blanco, Erika Patricia; Rivera Orozco, Mayulis de los Ángeles (2015). Pronunciamientos de la Corte Constitucional sobre el servicio doméstico en Colombia. Revista Jurídica Mario Alario D’Filippo, VII (14), pág 12-21.

\section{RESUMEN}

Este artículo es producto de los estudios que ha realizado, desde la línea de investigación "Derecho Laboral”, el grupo de investigación Derecho del Trabajo y Seguridad Social. Constituye un resumen de los avances legislativos y jurisprudenciales en materia de derechos laborales, reconocidos al grupo de trabajadores del servicio doméstico en Colombia, que parten de la expedición de la Constitución Política de 1991. Se trata de la norma superior inscrita en el derecho Internacional, que crea fuentes y cuerpos normativos garantistas que hoy salvaguardan derechos, que eran de goce y disposición exclusiva de trabajadores de empresas legalmente constituidas, y no de este grupo de trabajadores del servicio doméstico que laboran en condiciones desfavorables, o por lo menos en iguales circunstancias que la mayoría de los trabajadores colombianos.

\section{PALABRAS CLAVE}

Trabajadores Domésticos, Jurisprudencia Constitucional, Prima de Servicios, Convenio 189 de la OIT.

\section{ABSTRACT}

This paper is the final result of study and analysis made from the research group Labour Law and Social Security and the line "Labor Law". It's a summary of the legislative and jurisprudential progress on the labor rights acquired by the domestic workers in Colombia since the Political Constitution of 1991, the one that creates a regulatory body to safeguard the guarantees rights that were only delight and legal disposition of company workers.

\section{KEYWORDS}

Domestic workers, Constitutional Jurisprudence, Duty Bonus, Convention 189 of the ILO. 
"La dignidad no es la que da el poder, el dinero, la cultura, no. La dignidad nos la da el trabajo y un trabajo digno [porque habiendo tantos] sistemas sociales, políticos y económicos que han hecho que ese trabajo signifique aprovecharse de la persona" (PAPA FRANCISCO, 2013).

\section{INTRODUCCIÓN}

Desde la promulgación y entrada en vigencia de la Constitución Política colombiana de 1991, se crea en el país el escenario ideal para que los trabajadores colombianos puedan disponer y gozar de los derechos laborales y las garantías allí establecidas relacionadas con principios y reglas, en virtud de que cuenta no solo con normas positivas sino con derechos subjetivos y mecanismos que garantizan eficacia y justicia.

En razón de principios de especial protección, igualdad y progresividad, que emanan de la panorámica integral que establece la carta política, la Corte Constitucional emitió la Sentencia C-871, de noviembre de 2014, cuyo pronunciamiento se extiende al derecho a la prima de servicios. Esta prestación radicada exclusivamente en cabeza de los trabajadores de las empresas, toda vez que el código laboral establece que solo aquellas, estaban obligados a pagarla, fue razonablemente extendida a los trabajadores del servicio doméstico.

La Corte Constitucional exhorta al Congreso para que regule e incorpore al ordenamiento jurídico nacional, una ley que permita el goce efectivo de esta prestación a trabajadores que se dedican a prestar servicios domésticos, bajo la subordinación de un patrono que no es empresa. No menos importante resulta el primer pronunciamiento al respecto, de parte de la Organización Internacional del trabajo, organismo de derecho internacional, mediante Convenio 189 OIT de 2011, que regula el "Trabajo Decente", y señala la necesidad de hacer un "reconocimiento especial", a las trabajadoras y los trabajadores del servicio doméstico.

\section{LEGISLACIÓN LABORAL COLOMBIANA SOBRE TRABAJADORES DEL SERVICIO DOMÉSTICO}

En este aparte es menester hacer alusión al Decreto 13 de $1967^{5}$ y a la Ley 11 de $1988^{6}$ referidos a los trabajadores domésticos colombianos en los que se observa que desde allí se establecen acercamientos aunque con avances lentos pero progresivos, y de protección a los derechos laborales de este grupo de trabajadores, que podría

\footnotetext{
${ }^{5}$ Incorporan al Código Sustantivo del Trabajo las disposiciones de la Ley 73 de 1966. En su artículo 4o. menciona: “El artículo 171 del Código Sustantivo del Trabajo quedará así: "Edad mínima. (...) 2. Los menores de diez y ocho (18) años no pueden trabajar durante la noche, excepto en empresas no industriales y en el servicio doméstico, siempre que el trabajo no sea peligroso para su salud o moralidad." (Ministerio del Trabajo, 1967)

${ }^{6}$ Consagran unas excepciones al régimen del Seguro Social para los trabajadores del servicio doméstico. En su artículo 1o. menciona: "A partir de la vigencia de la presente ley, el trabajador del servicio doméstico que devengue una remuneración en dinero inferior al salario mínimo legal vigente, cotizará para el seguro social sobre la base de dicha remuneración. (...)" (Congreso de la Republica de Colombia, 1988)
} 
considerarse vulnerable, en la medida en que la mayoría son mujeres, incluso menores de edad, madres cabeza de familia, cuya relación se mantiene un tanto invisibilizada y sometida a la intimidad de los hogares y las familias independientemente de cuales se trate.

Partiendo de la Constitución Política de 1991, encontramos amplios desarrollos legales de sus principios y normas, los cuales se exponen a continuación.

\subsection{LEY 100 DE 1993}

El artículo 18 de esta ley, que trata sobre la base de cotización de los trabajadores dependientes de los sectores privado y público, señala: "La base para calcular las cotizaciones a que hace referencia el artículo anterior, será el salario mensual" vigente. El artículo 5 de la Ley 797 de 2003 introdujo una modificación al parágrafo $1^{\circ}$ del artículo 18 de la Ley 100 de 1993, al establecer que: "En ningún caso la base de cotización podrá ser inferior al monto del salario mínimo legal mensual vigente", salvo lo dispuesto para los trabajadores del servicio doméstico conforme a la Ley 11 de 1988.

\subsection{EL DECRETO 1295 DE 1994}

Determina la organización y la administración del Sistema General de Riesgos Profesionales (SGRP), y en su artículo 3o, que se refiere al campo de aplicación dispone lo siguiente:

El Sistema General de Riesgos Profesionales, con las excepciones previstas en el artículo 279 de la ley 100 de 1993, se aplica a todas las empresas que funcionen en el territorio nacional, y a los trabajadores, contratistas, subcontratistas, de los sectores público, oficial, semioficial, en todos sus órdenes, y del sector privado en general.

Como bien se desprende de la interpretación extensiva de la norma, debe concluirse que los trabajadores del servicio doméstico del sector privado se encuentran comprendidos en ella, aunque el Código Sustantivo del Trabajo no lo consagre expresamente. Contrario sensu, si la prestación dependiera exclusivamente de la interpretación exegética de la norma, dichos trabajadores podrían encontrarse sin cobertura para los riesgos laborales.

\subsection{LEY 1098 DE 2006}

Se trata del Código de la Infancia y la Adolescencia, que en su artículo 35 -que trata sobre la edad mínima de admisión al trabajo y derecho a la protección laboral de los adolescentes autorizados para trabajar-, establece: "La edad mínima de admisión al trabajo es los quince (15) años". Y agrega, en el mismo inciso primero:

(...) los adolescentes entre los 15 y 17 años requieren la respectiva autorización expedida por el Inspector de Trabajo o, en su defecto, por el Ente Territorial Local, y gozarán de 
las protecciones laborales consagradas en el régimen laboral colombiano, las normas que lo complementan, los tratados y convenios internacionales ratificados por Colombia, la Constitución Política y los derechos y garantías consagrados en este código.

En relación con aquellos adolescentes autorizados para trabajar, se establece en el inciso segundo que éstos “(...) tienen derecho a la formación y especialización que los habilite para ejercer libremente una ocupación, arte, oficio o profesión, a recibirla durante el ejercicio de su actividad laboral". Y finalmente, en su parágrafo único, se señala: "Excepcionalmente, los niños y niñas menores de 15 años podrán recibir autorización de la Inspección de Trabajo, o en su defecto del Ente Territorial Local, para desempeñar actividades remuneradas de tipo artístico, cultural, recreativo y deportivo. La autorización establecerá el número de horas máximas y prescribirá las condiciones en las que la actividad debe llevarse a cabo. En ningún caso el permiso excederá las catorce (14) horas semanales".

\subsection{LEY 1595 DE 2012}

Por medio de esta norma, se aprueba el Convenio sobre el trabajo decente para las trabajadoras y los trabajadores domésticos, Convenio $N^{\circ} 189$ adoptado el día 16 de Junio de 2011 durante la centésima reunión de la Conferencia General de la Organización Internacional del Trabajo, congregada en la ciudad de Ginebra, Confederación Suiza.

\subsection{DECRETO 721 DE 2013}

A través de este decreto, se reglamenta el numeral $\underline{4}$ del artículo $7^{\circ}$ de la Ley 21 de 1982, y se regula la afiliación de los trabajadores del servicio doméstico al Sistema de Compensación Familiar, lo que convierte a la familia en receptora de los beneficios de capacitación, recreación y ahorro que las Cajas de Compensación tienen para los trabajadores afiliados en razón del pago de los parafiscales.

\subsection{DECRETO 2616 DE 2013}

Desde la expedición de esta importante norma, que relaciona el salario con la seguridad social, el trabajador no podrá excusarse para no cotizar a pensión, por el hecho de que no haya podido trabajador el mes completo. Gracias a este decreto, el trabajador que sólo haya podido cotizar 2 o 3 semanas del mes al sistema general de pensiones, siempre podrá sumarlas a las que ya tiene y de esa manera seguir acumulándolas hasta alcanzar las semanas requeridas para acceder a su pensión de jubilación. Desde el 14 de febrero de 2014 , los trabajadores colombianos pueden hacer el pago de aportes a la seguridad social a través de su fondo de pensiones, no necesariamente por meses, sino por semanas. 


\subsection{RESOLUCIÓN 5094 DE 2013}

Se trata de una resolución del Ministerio de Salud y Protección Social que complementa la anterior, pues introduce una nueva categoría a la PILA, o planilla integrada de autoliquidación de aportes a la seguridad social. PILA cobija a los trabajadores afiliados al régimen subsidiado en salud, aun vinculados por periodos inferiores a un mes; es decir que adiciona el Decreto 2616 de 2013 en lo que se refiere a las cotizaciones, lo que en el Código Sustantivo del Trabajo no aparecía debidamente regulado.

\section{DERECHOS LABORALES ADQUIRIDOS PORELGRUPODETRABAJADORES DOMÉSTICOS, A TRAVÉS DE LA JURISPRUDENCIA}

En este aparte, analizaremos principios de extensión y progresividad, en las interpretaciones y el trabajo de la Corte Constitucional, como expresión de avances en materia de derechos de los trabajadores colombianos en general, y de los del servicio doméstico en particular.

Desde la promulgación de la Constitución de 1991 y a lo largo de su devenir histórico, la Corte Constitucional ha mostrado, a través de sus sentencias, su estirpe de guardiana y mejor intérprete de la Carta Política. La Corte Constitucional, en efecto, ha sido el principal órgano de defensa, promoción y protección de los derechos de los trabajadores, en especial los del servicio doméstico, independientemente del tipo de relación contractual. La Corte ha llevado a cabo una verdadera labor de reconocimiento y extensión de derechos. En efecto, ya desde la sentencia C 051 de 1995, la Corte Constitucional realzaba su loable labor de salvaguarda de la integridad y la supremacía de la Carta Política, y el ejercicio de la función exclusiva de

(...) conocer de los asuntos de constitucionalidad cuyo análisis le confía la misma constitución, en su condición de intérprete autorizado de reglas jurisprudenciales sobre el alcance de las normas constitucionales, en términos de lo dispuesto en los artículos 239 constitucional, y 44 de la Ley 270 de 1996, o ley de administración de Justicia.

A continuación, de manera muy breve, vale la pena traer a colación sus sentencias en torno a este tema, relevando los argumentos más significativos expuestos en cada una de ellas.

\subsection{SENTENCIA C-051 DE 1995}

A través de esta sentencia, la Corte Constitucional señala expresamente: "Si el servicio doméstico es un lujo, quienes lo disfrutan deben pagarlo en forma semejante a como se remunera a todos los trabajadores". Y en cuanto al auxilio de cesantía, advierte que la limitación de éste “(...) se opone a la elevación del nivel de vida de los servidores domésticos, elevación impuesta por principios de solidaridad social”, estimando como 
'limitación razonable que no es contraria a la Constitución' que el auxilio de cesantía de los trabajadores del servicio doméstico se liquide tan sólo sobre el salario recibido en dinero, conclusión que se desprende del análisis de las condiciones del servicio y "en especial la dificultad práctica de dar un tratamiento uniforme a lo que se recibe como salario en especie". En criterio de la Corte, además, podría correrse el riesgo de desmejorar las condiciones de vida de estos trabajadores, como consecuencia del temor provocado "por la cuantificación de todo lo que integra el salario en especie".

\subsection{SENTENCIA C-372 de 1998}

La Corte afirma que: "Una jornada laboral excesiva contradice los principios de la dignidad humana y las condiciones justas en que han de cumplirse las tareas domésticas". Resulta indispensable, por tanto, fijar límites al período de trabajo que exceda la jornada máxima ordinaria, puesto que un límite por fuera quebrantaría las garantías mínimas del trabajador. Las anteriores condiciones permiten que la norma acusada pueda ser exequible, de modo que aun cuando sea posible la exigencia de laborar durante períodos superiores a la jornada máxima fijada en la ley, para la Corte es razonable que en ningún caso los trabajadores del servicio doméstico laboren más de 10 horas diarias, y en el evento de requerir servicios más allá de este límite, debe reconocerse como pago de horas extras, en términos de la legislación laboral.

\subsection{SENTENCIA C-310 DE 2007}

En esta sentencia, la Corte considera que: “(...) no es justo que entre personas que tienen como empleador al jefe de hogary desempeñen tareas para la familia, exista un tratamiento diferencial en lo concerniente a la liquidación de las cesantías, por la simple circunstancia de que unas realizan labores 'de aseo, cocina, lavado, planchado, vigilancia de niños, y demás labores inherentes al hogar' y otras se encarguen de conducir automotores". Para la Corte, esta distinción es discriminatoria, puesto que no está sustentada en "una justificación objetiva y razonable".

Según el alto Tribunal, la norma acusada incurre en degradación en tanto en cuanto niega el "carácter salarial a la remuneración en especie que reciben los trabajadores del servicio doméstico"; añade la Corte, en sustentación de lo antedicho, que esta exclusión implica "una sensible reducción de los ingresos de esos empleados hacia la eventualidad del desempleo o las necesidades de vivienda y educación, que corresponden a las finalidades asignadas legalmente a esa prestación social".

La Corte señala-tal como lo advierten la demandante, el Procurador, y otros intervinientes, cuyos argumentos fueron analizados antes de dictar la sentencia-, que si se considera, de conformidad con los dictados superiores, que el salario en especie es igualmente salario, “(...) no se explica cómo el legislador desconoce su naturaleza retributiva, afectando de 
paso el ingreso del trabajador doméstico (...)". En efecto, por disposición de la norma acusada, los empleados del servicio doméstico no pueden satisfacer sus necesidades esenciales por no contar con la totalidad de su remuneración como base de liquidación de sus cesantías.

La norma revisada comporta, según la Corte Constitucional, no sólo una "ostensible violación del derecho al trabajo" consagrado en el artículo 25 de la Constitución Política - del cual forma parte la figura de la remuneración-, sino también al 'principio de universalidad de las prestaciones sociales'". Dentro de las contingencias típicas, cubiertas por un sistema contributivo de seguridad social, "se encuentra el desempleo", cuya eventualidad busca precaver el pago de las cesantías. Así, la Corte declara la inexequibilidad de la expresión "sólo", contenida en el artículo 252, numeral $2^{\circ}$ del Código Sustantivo del Trabajo, y queda entendido que el auxilio de cesantía de los empleados del servicio doméstico, será pagadero igual que a los demás trabajadores colombianos, un salario por año de servicio, y proporcional por fracción de año; en ningún caso será inferior al salario mínimo legal mensual vigente

\subsection{SENTENCIA C-871 DE 2014}

En este caso específico, la Corte sostuvo que “(...) la norma demandada, al excluir a las trabajadoras y trabajadores del servicio doméstico del pago de la prima de servicios, genera un déficit de protección de este grupo social, y un trato desigual frente a los demás trabajadores". Considera, además, que esa postura conceptual ha sido revaluado, en el entendido de que entraña una concepción equívoca de lo que es el trabajo doméstico, muy a pesar de quienes argumentan que es razonable dar un trato diferencial, en atención a que en sus orígenes la prima de servicios fue una manera de "retribuir a los trabajadores con las utilidades de la empresa".

Desde esta perspectiva, la Corte "explicó que (i) la prima de servicios sí se inspiró en una prestación que se denominaba 'reparto de utilidades', pero no es idéntica; así lo demuestra el hecho de que el Legislador la define en torno a criterios de patrimonio de la empresa y salario del trabajador, y no en relación con las utilidades de las unidades productivas; (ii) la prima puede concebirse de forma amplia como una retribución por los beneficios económicos y sociales, que obtiene el empleador por el trabajo de sus empleados; (iii) el trabajo doméstico genera beneficios económicos y sociales a las familias, pues (iii. 1) les permite salir del hogar a generar ingresos y (iii.2) brinda cuidados a las personas más vulnerables del hogar como los niños y los ancianos, y finalmente, (iv) la distinción afecta a un grupo social vulnerable".

Finalmente, la Corte Constitucional exhorta al Legislador "para que implemente el pago de la prima de servicios a los y las trabajadoras del servicio doméstico, dando aplicación al principio de progresividad y, por lo tanto, estableciendo la obligación inicialmente para 
las familias de estratos altos, o de mayores ingresos, y adoptando las medidas pertinentes para la ampliación progresiva del derecho" a las demás familias que libremente contratan a esta clase de trabajadores.

\section{CONCLUSIONES}

No obstante el lento avance en la concesión de derechos laborales a este grupo de trabajadores vulnerables, como son los del servicio doméstico, desde hace 48 años se vienen planteando en Colombia directrices para su protección progresiva y para mejorar sus condiciones de trabajo.

Partiendo de la expedición de la Carta Política de 1991, se obedece a la correspondencia entre ley y norma superior, principios, derechos y garantías constitucionales, en beneficio de la igualdad y la equidad de todos los trabajadores en el territorio colombiano; se trata de una legislación protectora y progresiva que no discrimina negativamente, sino que por el contrario equilibra y valora el trabajo sin tener en cuenta el tipo de trabajador, ni la clase de labores que se llevan a cabo, ni la modalidad del salario que ellos reciben.

En respuesta a las necesidades de superación de múltiples discriminaciones y vejámenes sufridos por este grupo de trabajadores, y en consonancia con el avance de la civilización, la legislación colombiana se ha puesto a la vanguardia del ordenamiento jurídico internacional, después de arduas luchas legislativas y jurisprudenciales, alcanzando logros significativos en el camino de la evolución del reconocimiento y la extensión de derechos laborales que solo eran reconocidos a trabajadores distintos a los del servicio doméstico.

Uno de los logros más importantes en la batalla contra el sistema económico imperante en Colombia -denominado Capitalismo Mixto, por su relación con la legislación vigente y los estigmas sociales-, ha sido el reconocimiento, por vía de extensión jurisprudencial, de la Prima de Servicios para los Trabajadores del Servicio Doméstico. En efecto, obedeciendo a las exhortaciones de la Corte Constitucional, el Congreso y el Gobierno Nacional pueden hacer posible la realización y el goce de derechos laborales plenos a este grupo de trabajadores, especialmente su derecho a la prima de servicios, dándole prevalencia a los principios de dignidad e igualdad, y reivindicando su condición de grupo vulnerable abusado en sus derechos humanos, y discriminado como consecuencia de la escasa legislación que los protegiera.

\section{REFERENCIAS BIBLIOGRÁFICAS}

Sentencia C-051/95, expediente D-696 (Corte Constitucional febrero 16, 1995).

Sentencia C-372/98, expediente D-1923 (Corte Constitucional julio 21, 1998).

Sentencia C-310/07, expediente D-6512 (Corte Constitucional mayo 3, 2007). 
Sentencia C-871/14, expediente D-10213 (Corte Constitucional noviembre 2014).

Congreso de la Republica de Colombia 2006, noviembre 8. Ley 1098 de 2006. Código de la Infancia y la Adolescencia. Bogotá D. C., Colombia .

Congreso de la Republica de Colombia, 1988, enero 19. Ley 11 de 1988. Excepciones en el régimen del Seguro Social para los trabajadores del servicio doméstico. Bogotá D. C., Colombia.

Congreso de la Republica de Colombia, 1993, diciembre 23. Ley 100 de 1993. Sistema de Seguridad Social Integral. Bogotá, D. C., Colombia.

Congreso de Republica de Colombia, 2012, diciembre 21. Ley 1595 de 2012. Aprobaciòn del "Convenio sobre el trabajo decente para las trabajadoras y los trabajadores domesticos, 2011, Número 189". Bogotá, Colombia.

Corte Constitucional Colombiana, 2015. Corte Constitucional. Retrieved septiembre 10, 2015 Corte: http://www.corteconstitucional.gov.co/lacorte/

Ministerio de Gobierno de la Republica de Colombia. (1994, junio 22). Decreto 1295 de 1994. Organización y administración del Sistema General de Riesgos Profesionales. Bogotá D. C., Colombia.

Ministerio de Salud y protección social, 2013, noviembre 29. Resolucion 5094 de 2013. Planilla integrada de autoliquidación de aportes PILA, de acuerdo con lo establecido en el Decreto número 2616 de 2013. Bogotá D. C., Colombia.

Ministerio del Trabajo - Presidente de la Republica de Colombia. (2013, noviembre 20). Decreto 2616 de 2013. Por medio del cual se regula la cotización a seguridad social para trabajadores dependientes que laboran por períodos inferiores a un mes, se desarrolla el mecanismo financiero y operativo de que trata el artículo 172 de la Ley 1450 de 2011 y se dictan di. Bogotá D. C., Colombia.

Ministerio del Trabajo. (1967, enero 4). Decreto 13 de 1967. Por el cual se incorporan al Código Sustantivo del Trabajo las disposiciones de la Ley 73 de 1966. Bogotá D. C., Colombia.

Papa Francisco - Sumo Pontifice, 2013, mayo 1. Audiencia Publica, Día del Trabajador, Ciudad del Vaticano.

Presidencia de la Republica de Colombia, 2013, abril 15, Decreto 721 de 2013. Reglamenta el numeral 4 del artículo $7^{\circ}$ de la Ley 21 de 1982 y regula la afiliación de los trabajadores del servicio doméstico al Sistema de Compensación Familiar. Bogotá D. C., Colombia . 